\title{
Notch signaling during human T cell development
}

Tom Taghon, Els Waegemans* and Inge Van de Walle*

Notch signaling during human $\mathrm{T}$ cell development ...................... 1

1 Human T cell development...................................................... 2

2 Notch signaling profile ......................................................... 5

3. Stage-specific Notch signaling requirements ....................... 11

3.1 Induction of T-lineage specification ................................. 11

3.2 Induction of T-cell commitment. .................................... 12

3.3 TCR rearrangements, $\beta$-selection and beyond. ................ 15

4. TCR- $\alpha \beta$ versus TCR- $\gamma \delta$ lineage choice .................................... 19

5. Conclusion.......................................................................... 23

Abstract Notch signaling is critical during multiple stages of $T$ cell development in both mouse and human. Evidence has emerged in recent years that this pathway might regulate T-lineage differentiation differently between both species. Here, we review our current understanding of how Notch signaling is activated and used during human T cell development. First, we set the stage by describing the developmental steps that make up human T cell development before describing the expression profiles of Notch receptors, ligands and target genes during this process. To delineate stage-specific roles for Notch signaling during human T cell development, we subsequently try to interpret the functional Notch studies that have been performed in light of these expression profiles and compare this to its suggested role in the mouse.

\footnotetext{
* E. Waegemans and I. Van de Walle contributed equally.

Contact: T. Taghon

Department of Clinical Chemistry, Microbiology and Immunology, Ghent University

Hospital, Ghent University, Ghent 9000, Belgium

Email: tom.taghon@ugent.be
} 


\section{Human T cell development}

$\mathrm{T}$ cell development in postnatal life is a prolonged developmental process in which bone-derived multipotent hematopoietic progenitor cells seed the thymus (thymus seeding progenitors, TSPs) to become gradually reprogrammed into fully mature and functional $\mathrm{T}$ lymphocytes. The distinct developmental steps, as schematically illustrated in Figure1, are synchronized with the migration of the developing thymocytes towards specific niches in the thymus that provide the necessary stage-specific environmental factors that are needed for further differentiation (Petrie and Zuniga-Pflucker, 2007). In recent years, much progress has been made with respect to the identification and characterization of these early $\mathrm{T}$ cell progenitors (ETPs) in human. Within the pool of intrathymic CD34 ${ }^{+} \mathrm{CD} 1 \mathrm{a}^{-}$uncommitted $\mathrm{T}$ cell progenitors (population B, Figure 1) (Blom and Spits, 2006), Crooks and colleagues characterized 3 distinct subsets of progenitor cells that can be discriminated based on differential CD7 expression (Hao et al., 2008). The $\mathrm{CD}^{+} 4^{+} \mathrm{CD} 1 \mathrm{a}^{-} \mathrm{CD} 7^{-}$subset seems to be the most immature subset of progenitors as it is mainly, but not exclusively, composed of CD38 $8^{-/ \text {low }}$ progenitor cells, consistent with their potential to generate lymphoid, myeloid and even erythroid cells (Hao et al., 2008; Weerkamp et al., 2006a). In contrast, $\mathrm{CD} 34^{+} \mathrm{CD} 1 \mathrm{a}^{-} \mathrm{CD} 7^{\text {int }}$ cells have lost myeloid and erythroid potential and thus resemble lymphoid primed progenitors that were earlier identified in umbilical cord blood by the same laboratory (Hao et al., 2001; Hoebeke et al., 2007). Both the $\mathrm{CD}^{-}$and $\mathrm{CD}^{\text {int }}$ subset express CD10, and both populations have been identified in cord blood and adult bone marrow, raising the possibility that the human thymus can be colonized by both types of progenitor cells (population A, Figure 1) (Six et al., 2007; Doulatov et al., 2010; Galy et al., 1995). While $\mathrm{CD} 34^{+} \mathrm{CD} 7^{\text {int }} \mathrm{CD} 10^{+}$cells in the bone marrow have been proposed to be T-lineage committed prethymically (Klein et al., 2003), and while there is evidence from an in vitro xenograft model that only $\mathrm{CD}^{\text {int }}$ cells can colonize the thymus (Haddad et al., 2006), no in vivo models have been successfully used to demonstrate thymus homing from either subset (Six et al., 2007; Doulatov et al., 2010). In addition, the selective homing of $C D 7^{\text {int }}$ cells does not fit with earlier experiments in which $\mathrm{CD} 34^{+} \mathrm{CD} 7^{-}$progenitor cells were 
successfully used to study human T cell development using the same xenograft foetal thymus organ culture (FTOC) model (Taghon et al., 2002; Hoebeke et al., 2007), raising the possibility that few, but physiologically relevant and sufficient, $\mathrm{CD}^{-}$cells can enter the thymus. Furthermore, it remains to be established whether both $\mathrm{CD}^{-}$and $\mathrm{CD}^{\text {int }}$ cells enter as separate entities or if one subset leads to the development of the other. While it seems unlikely that CD7 ${ }^{\text {int }}$ cells give rise to more multipotent $\mathrm{CD}^{-}$cells, the reverse cannot be excluded, especially since Notch activation results in induction of CD7 expression (Jaleco et al., 2001; De Smedt et al., 2002; Van de Walle et al., 2009; Magri et al., 2009; Van de Walle et al., 2011). Moreover, there is evidence that extrathymic $\mathrm{CD} 7{ }^{\text {int }}$ progenitor cells still contain myeloid potential (Doulatov et al., 2010; Hoebeke et al., 2007), in contrast to the phenotypically similar population within the postnatal thymus (Hao et al., 2008). However, the apparent discrepancies might be due to the technical approaches used. Since sustained Notch signaling is required to suppress B cell development (Taghon et al., 2005; Krueger et al., 2006), it is possible that $\mathrm{CD} 34^{+} \mathrm{CD} 7^{\text {int }}$ progenitors have just initiated the T-lineage specification program as they still display B-lineage differentiation potential in vitro. Further studies using clonal approaches will be required to fully resolve this issue.

Within the $\mathrm{CD} 34^{+} \mathrm{CD}^{-}$uncommitted pool of progenitors, the third and by far largest - subset of thymocytes expresses high levels of CD7 and mainly comprises T/NK progenitors, resembling DN2a cells in the mouse (Yui et al., 2010). During postnatal life, these cells are most likely derived from Notch-primed $\mathrm{CD} 34^{+} \mathrm{CD} 1 \mathrm{a}^{-} \mathrm{CD} 7^{-}$ and/or $\mathrm{CD} 34^{+} \mathrm{CD} 1 \mathrm{a}^{-} \mathrm{CD} 7^{\text {int }}$ cells as they do not seem present within the bone marrow or peripheral blood (our own unpublished observations). In addition, these cells display high expression levels of $\mathrm{T}$ lineage specific genes and have faster T-lineage kinetics compared to the other uncommitted subsets, indicating that these cells have been specified toward the T-cell lineage (Hao et al., 2008; Van de Walle et al., 2009). Further differentiation induces T-cell commitment which is complete when the immature T cell marker CD1a is expressed (population C, Figure 1) (Blom and Spits, 2006). 


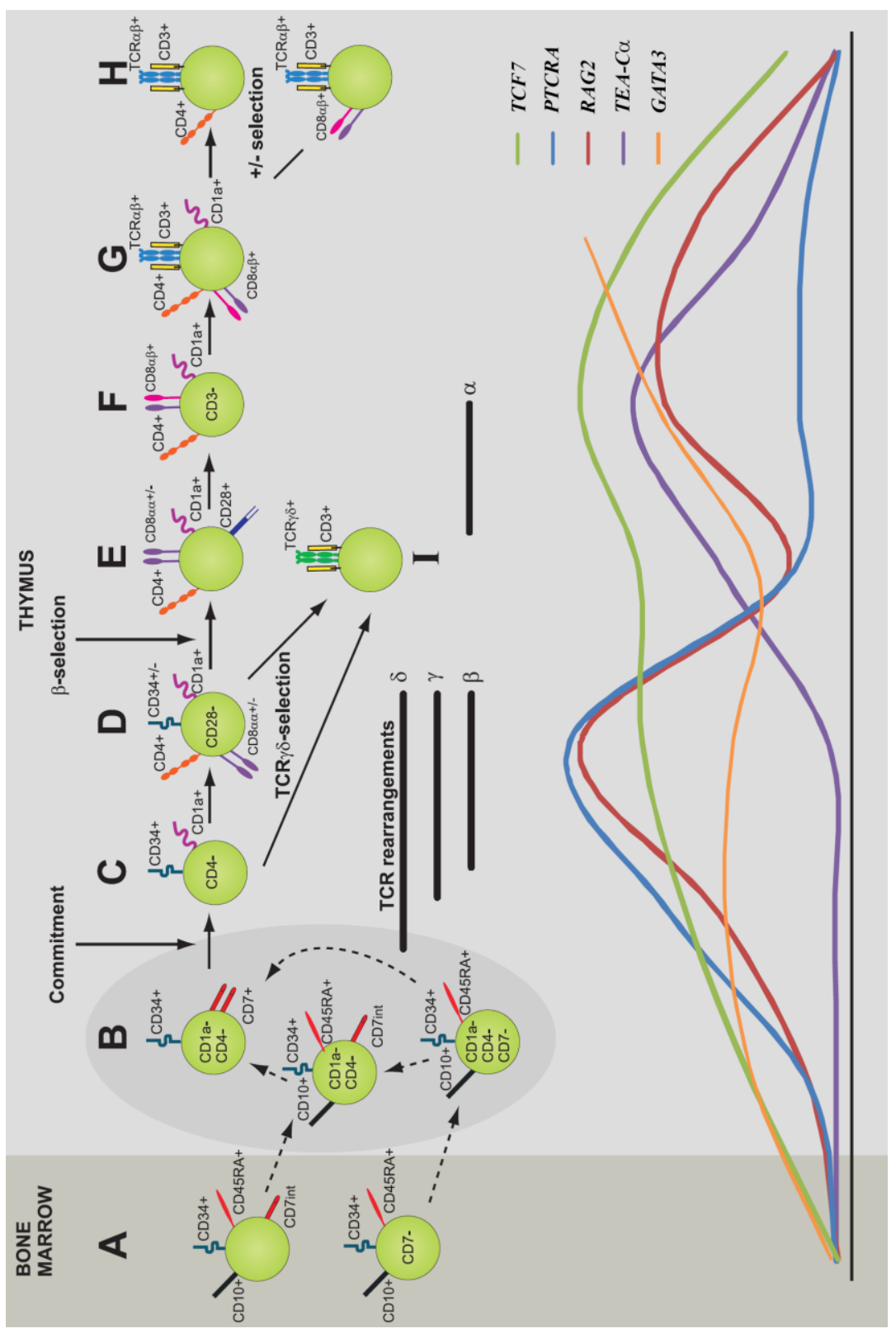

Fig 1. Schematic overview of the different developmental stages that characterize human $T$ cell development. Gene expression levels are indicative for the change in expression for each individual gene from one stage to the other, but do not provide insights into the differential expression levels between these genes. Data for GATA3 in population $\mathrm{H}$ is not provided due to the high difference in expression between CD4 and CD $8 \alpha \beta$ T cell populations. 
During these specification and commitment processes, TCR rearrangements at the TCRD, TCRG and TCRB loci are initiated (Dik et al., 2005) and are fully active in the subsequent immature single positive CD4 (ISP4) subset of developing thymocytes as also illustrated by their high levels of $R A G$ and PTCRA (coding for $\mathrm{pT} \alpha$ ) expression (population D, Figure 1), corresponding to murine DN3a cells (Taghon et al., 2006). In-frame rearrangements that yield a TCR- $\delta$ and TCR- $\gamma$ chain will mainly result in the generation of $\mathrm{TCR} \gamma \delta^{+} \mathrm{CD}^{+} \mathrm{T}$ cells (population I, Figure 1), while a functional TCR- $\beta$ chain will pair with the surrogate TCR $\alpha$ chain, pT $\alpha$, to induce the process of $\beta$-selection. This event is characterized by the acquisition of CD28 expression (population E, Figure 1, corresponding to murine DN3b cells) (Taghon et al., 2006; Taghon et al., 2009; Blom and Spits, 2006), extensive but temporarily Notch-dependent proliferation and rapid differentiation into $\mathrm{CD} 4^{+} \mathrm{CD} 8 \alpha \beta^{+}$double positive (DP) thymocytes (population F, Figure 1). It is important to note that some of the immature $\mathrm{CD} 4^{+} \mathrm{CD} 3^{-} \mathrm{CD} 28^{-}$ISP4 cells also express CD8 $\alpha \alpha$ homodimers, indicating that in human $\mathrm{CD} 4^{+} \mathrm{CD} 8 \alpha \alpha^{+}$ DP thymocytes do not necessarily represent true $\alpha \beta$-lineage DP thymocytes that passed through the $\beta$-selection checkpoint (Taghon et al., 2009; Joachims et al., 2006; Carrasco et al., 1999). Subsequently, $\mathrm{CD} 4^{+} \mathrm{CD} 8 \alpha \beta^{+}$DP cells initiate rearrangement of the TCR- $\alpha$ chain, as revealed through the onset of sterile T-early $\alpha$ transcript (TEA-C $\alpha$ ) expression (Figure 1), to generate a fully functional TCR$\alpha \beta$ complex (population G, Figure 1). Finally, positive and negative selection determines which cells further mature into $\mathrm{CD}^{+}$or $\mathrm{CD}^{+}$ SP TCR $\alpha \beta$ T cells (population H, Figure 1) (Plum et al., 2008).

\section{Notch signaling profile}

As in the mouse, the Notch signaling pathway is involved in various stages of T cell development in human. Given the fact that the Notch signaling pathway is composed of several receptors and ligands that can activate a broad range of different target genes, we will first de- 
scribe our current understanding of the expression patterns of these components during human $\mathrm{T}$ cell development. This will serve as point of reference for interpreting the functional studies that have been performed thus far.

Migration through the thymus is critical for developing thymocytes to receive the appropriate stage-specific developmental cues for further differentiation. As a result, characterization of the expression of Notch ligands by stromal cells at specific sites of the thymus will provide a hint of the possible involvement of these Notch signal initiating components during human $\mathrm{T}$ cell development. In collaboration with the Kyewski lab (Gotter et al., 2004), we recently determined the expression pattern of Notch ligands in human cortical and medullary thymic epithelial cells (cTEC and mTEC, respectively) using quantitative PCR (Q-PCR) and flow cytometry, thereby providing insights into the Notch ligands that possibly support early stages of human thymocyte development (as shown by expression in cTECs) and those that may be involved in the final maturation stages of $\mathrm{T}$ cell development (as shown by expression in mTECs) (Van de Walle et al., 2011). Both approaches revealed a predominant expression of JAG2, in 70-90\% of both TEC subsets as defined using flow cytometry. Between 10 and $20 \%$ of cTECs expressed DLL4. In contrast, only very low amounts of Delta-Like-1 protein were detected in no more than $10 \%$ of cTECs and JAG1 was mainly expressed by mTECs, as revealed through Q-PCR only due to lack of suitable antibodies. A schematic overview of these expression patterns is presented in Figure 2. From this, one could predict that Jagged2 might play a major role during human $\mathrm{T}$ cell development. Unfortunately, the generation of a Jagged 2 deficient human thymic microenvironment is currently impossible, although approaches using hES cells might become feasible in the future (Green et al., 2011). As discussed further, the specific expression of DLL4 in cTECs is consistent with its requirement for the induction of T-lineage differentiation in TSPs, as is the medullary expression of the weak Notch ligand JAG1 as Notch signaling does not seem to play an obvious role in the final maturation stages of $\mathrm{T}$ cell development. 


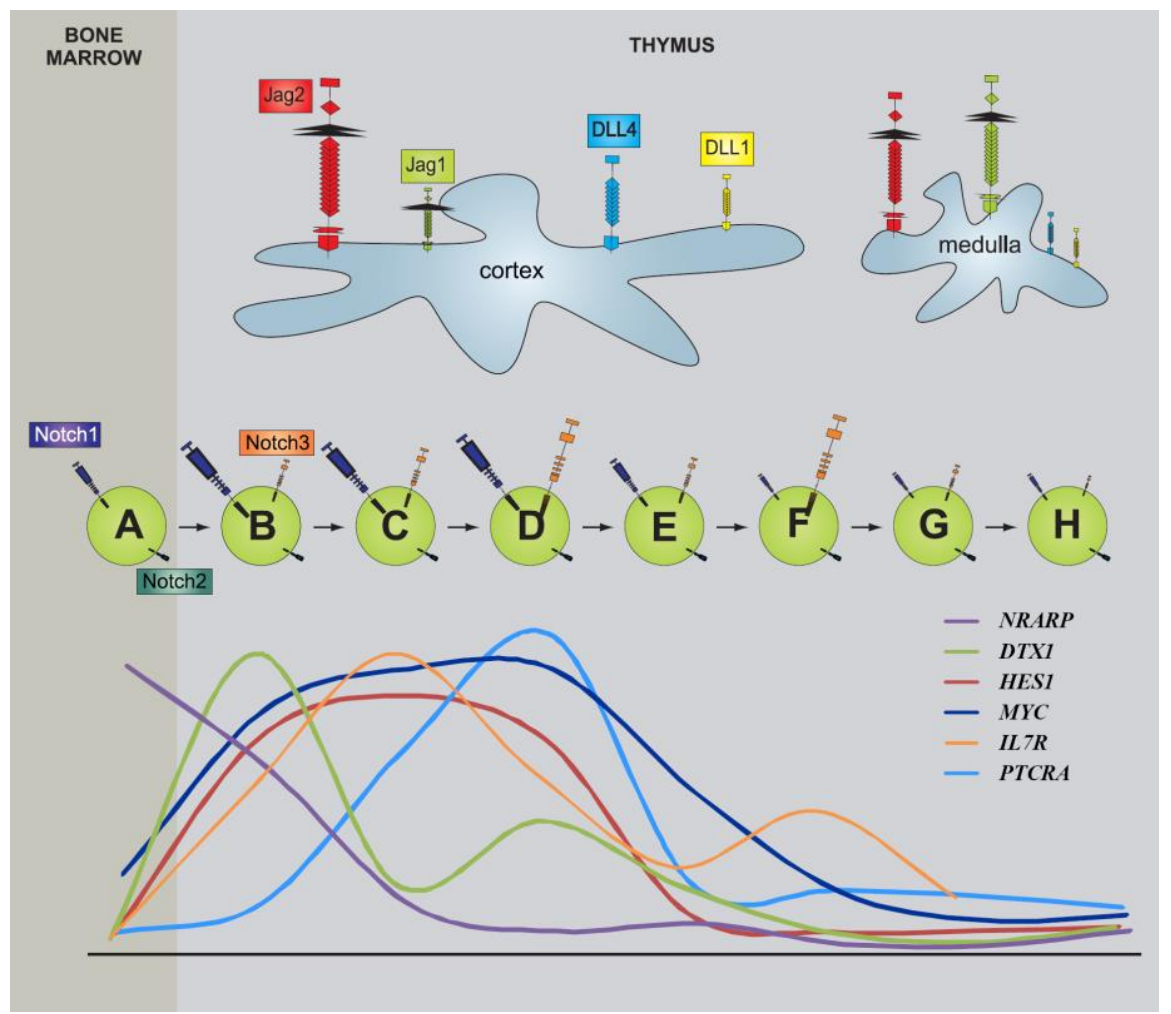

Fig.2 Overview of the expression of the Notch signaling components during human T cell development. The size of the Notch ligands and receptors is a measure for their expression level. The expression levels for the Notch downstream target genes are indicative for the change in expression for each individual target gene from one stage to the other, but do not provide insights into the differential expression levels between these genes. Data for IL7R in population $\mathrm{H}$ is not provided due to the high difference in expression between CD4 and CD8 $\alpha \beta$ T cell populations.

While the expression data for the Notch ligands seems mostly consistent with data in the mouse, with perhaps the exception of the high Jag2 expression levels that still need confirmation at the protein level (Heinzel et al., 2007), some differences can be observed between both species with respect to the expression patterns of the Notch receptors. While TSPs (population A) express both NOTCHI and $\mathrm{NOTCH} 2$, but not $\mathrm{NOTCH} 3$, uncommitted $\mathrm{CD} 34^{+} \mathrm{CD}^{-}$human postnatal thymocytes (population B) express, in addition to $\mathrm{NOTCH} 1$ and NOTCH2, also significant levels of $\mathrm{NOTCH} 3$, and this expression persists into the DP stages of $\mathrm{T}$ cell development (populations C-G) before shutting down in mature CD4 and CD8 SP cells (population H) (Van de Walle et al., 2009; Ghisi et al., 2011). While 
we recently confirmed these findings at the protein level (Van de Walle et al, manuscript in preparation), the kinetics of NOTCH3 expression in human are earlier compared to those observed during mouse $\mathrm{T}$ cell development, raising the possibility that this receptor may be actively involved during the initial Notch dependent stages of human T-lineage differentiation. However, NOTCH1 is also clearly expressed during the early steps of $\mathrm{T}$ cell development until the human $\beta$-selection checkpoint (populations B-D), raising the possibility that this remains the major Notch receptor during these early stages of $\mathrm{T}$ cell development, analogous to the situation in mouse (Suliman et al., 2011; Shi et al., 2011; Radtke et al., 1999; Wolfer et al., 2002; Wilson et al., 2001). Also NOTCH2 mRNA can clearly be detected throughout T cell development (Van de Walle et al., 2009), but at levels around 10-fold lower compared to NOTCHI and $\mathrm{NOTCH} 3$, predicting lower chances to interact with Notch ligands on the surrounding stromal cells.

Strikingly, we observed significant differences in the expression profiles of the major Notch target genes NRARP, DTX1, HES1, MYC and PTCRA during human T cell development (illustrated graphically in Figure 2) (Taghon et al., 2009; Van de Walle et al., 2009). $N R A R P$ is the only Notch target gene that is already expressed in extrathymic progenitors (population A) and its expression is maintained in uncommitted postnatal thymocytes (population B) before declining upon T cell commitment (population C). In contrast, DTXI is absent in TSPs (population A) but is specifically upregulated in early uncommitted $\mathrm{T}$ cell progenitors (population $\mathrm{B}$ ) before immediately declining again upon T-lineage commitment (population $\mathrm{C}$ ). At present, it is unclear which $\mathrm{CD}_{3}{ }^{+} \mathrm{CD}^{-}$subpopulations are responsible for DTXI expression, but such information will be of interest for characterizing the cells that receive the first Notch triggers (Sambandam et al., 2005). A smaller, second wave of DTX1 expression can be observed just before $\beta$-selection (population $D$ ), in DN3a-like cells that express high levels of another Notch target gene PTCRA, which appropriately is only expressed in these TCR rearranging cells, awaiting the functional production of a TCR- $\beta$ chain to induce $\beta$-selection and further differentiation. While HESI and $M Y C$ are also induced upon initiation of $\mathrm{T}$ cell development in $\mathrm{CD} 34^{+} \mathrm{CD} 1^{-}$uncommitted thymocytes, their expression, in contrast 
to $D T X 1$, is maintained in $\mathrm{CD} 34^{+} \mathrm{CD} 1^{+}$committed and subsequent $\mathrm{T}$ cell progenitors until the cells receive a preTCR signal and pass through the $\beta$-selection checkpoint. Following this $\beta$-selection checkpoint, no significant expression of any of these Notch downstream targets can be detected, consistent with the requirement for the initiation of TCRA gene rearrangements as documented through the induction of expression of sterile TEA-C $\alpha$ transcripts, a process that is inhibited through Notch signaling (Van de Walle et al., 2009; Taghon et al., 2009). The only exception to this is NOTCH3, a gene that can be upregulated downstream of Notch1 signaling (Palomero et al., 2006; Weng et al., 2006; Van de Walle et al., 2011). In contrast to NOTCH1, NOTCH3 expression is again upregulated following $\beta$-selection before being shut off in mature SP CD4 and CD8 cells.

Although we could show that HES1, DTX1, NRARP, MYC, PTCRA and NOTCH3 are also Notch dependent in human thymocytes, albeit to different degrees (Van de Walle et al., 2009; Taghon et al., 2009), their highly diverse expression profiles suggest that additional regulatory mechanisms must be involved in controlling their expression. $I L 7 R$ was also suggested to be a direct Notch target during human $\mathrm{T}$ cell development (Gonzalez-Garcia et al., 2009; Magri et al., 2009), but nobody thus far has been able to show any short-term Notchdependent effects on $I L 7 R$ expression in primary human thymocytes ((Gonzalez-Garcia et al., 2009; Magri et al., 2009) and our own unpublished observations). In addition, this gene also displays a unique expression pattern during human $\mathrm{T}$ cell development that is distinct from any of the other Notch target genes (Figure 2). As suggested initially, differential Notch-dependency of these downstream target genes may partially explain their differential expression patterns, however, it cannot account for all of the observed differences as for instance the profiles of DTXI and NRARP, on the one hand, and that of PTCRA, on the other hand, are too distinct. This is also exemplified by $\mathrm{NOTCH} 3$, which can be a Notch1 downstream target gene, especially during the early stages of $\mathrm{T}$ cell development (Van de Walle et al., 2011; Weerkamp et al., 2006b; Neves et al., 2006), but the absence of expression of any other Notch downstream target gene, as well as of the Notch1 receptor itself at that same developmental stage, indicate that other molecular mechanisms are driving 
this expression. The need for additional regulatory inputs, such as feed-forward mechanisms that take over following a Notchdependent initial induction, is also obvious from the fact that Notch signaling by itself, as provided in an OP9 coculture system through excess expression of $D L L 1$, is not sufficient to maintain the same expression levels of most of these genes compared to their ex vivo isolated counterparts (Van de Walle et al., 2009). The exceptions to this are DTX1 and NRARP, not accidently the most Notch-dependent target genes that we could find (Van de Walle et al., 2009; Taghon et al., 2009). Thus, it remains to be investigated if perhaps autoregulatory mechanisms, as documented for HESl (Hirata et al., 2002), or other transcriptional regulators, as also illustrated previously in the mouse (Ikawa et al., 2006), regulate these processes. Given the recent finding that mir-150 is involved in turning off NOTCH3 expression upon human T cell maturation (Ghisi et al., 2011), it will also be critical to investigate the involvement of noncoding RNAs or other epigenetic phenomena in these settings.

Strikingly, with the exception of the apparent global silencing of Notch target genes following $\beta$-selection, the differential expression of the human Notch target genes is very distinct from what is observed during mouse $\mathrm{T}$ cell differentiation as all of these genes are gradually upregulated during the initial stages of murine $\mathrm{T}$ cell development before peaking at the DN3a stage (Taghon et al., 2006; David-Fung et al., 2006; Tydell et al., 2007; Weng et al., 2006). These findings suggest that the Notch signaling pathway, and its individual components, are used differently during $\mathrm{T}$ cell development in both species. As discussed below, we believe that at least some of these apparent discrepancies help to explain some of the functional differences that have been observed with respect to the role of Notch signaling during mouse and human $\mathrm{T}$ cell development since the same target genes have to integrate in different stage-specific regulatory networks. 


\section{Stage-specific Notch signaling requirements}

The use of conditional knockout mice has significantly advanced our understanding of the role of these individual Notch signaling components during mouse $\mathrm{T}$ cell development. However, such an approach hasn't been easily accessible thus far in a human setting, with the exception of the recently generated Notch receptor specific antibodies that haven't been widely used yet (Wu et al., 2010; Li et al., 2008). In anticipation also of gene-targeting studies in human embryonic stem cells (Hockemeyer et al., 2009; Hockemeyer et al., 2011) that can subsequently be used for studying the function of any desired gene during $\mathrm{T}$ cell development (Vandekerckhove et al., 2011; Timmermans et al., 2009; Galic et al., 2006), human Notch studies have been limited to the use of less specific tools, such as pharmacological $\gamma$-secretase inhibitors (GSIs), or 'all or nothing' approaches, for instance using stromal cocultures in the presence or absence of a Notch ligand and overexpression studies using intracellular Notch $(I C N)$ or the dominant-negative mutant of Mastermindlike-1 (DNMAML1). We will now discuss the functional implementation of these studies in light of the expression patterns of the individual Notch signaling components at specific stages of human $\mathrm{T}$ cell development.

\subsection{Induction of T-lineage specification}

In the mouse, the Delta-Like-4/Notch1 interaction is considered to be the main driving force for the Notch-dependent initiation of T cell development since both Notchl and Dll4 conditional deletion studies have provided unambiguous evidence for this (Koch et al., 2008; Radtke et al., 1999; Wilson et al., 2001; Hozumi et al., 2008; Feyerabend et al., 2009), in contrast to for instance DLL1 (Hozumi et al., 2004) or Notch3 (Suliman et al., 2011; Shi et al., 2011) knockout approaches. Absence of either Notchl or Dll4 inhibits T cell development and results in differentiation of other hematopoietic lineages instead, such as B, NK and myeloid cells. In human, it is clear from ICN (De Smedt et al., 2002) and DNMAML1 (Taghon et 
al., 2009) overexpression experiments, GSI inhibition data (De Smedt et al., 2005; Van de Walle et al., 2009) and stromal cocultures data (De Smedt et al., 2004; La Motte-Mohs et al., 2005; Lefort et al., 2006; Benne et al., 2009; Awong et al., 2009; Van de Walle et al., 2011) that Notch is equally important in humans to induce T cell development at the expense of other hematopoietic cell types. In this setting, Notch seems to act as a rheostat in which graded levels of signaling affect the hematopoietic lineage outcome (De Smedt et al., 2005; Lefort et al., 2006; Jaleco et al., 2001). Both functional studies using GSI (De Smedt et al., 2005; Van de Walle et al., 2009) and the Notch target gene expression profile (Figure 2, (Van de Walle et al., 2009; Taghon et al., 2009)) suggest that a strong Notch signal is required for driving the T-lineage specification process (Van de Walle et al., 2009). DTX1, HES1 and MYC are specifically upregulated in uncommitted $\mathrm{CD} 34^{+} \mathrm{CD}^{-}$thymocytes compared to extrathymic progenitors, while NRARP expression is maintained (Figure 2). Given that only NOTCH1 and NOTCH2 seem to be expressed by TSPs, and that Delta-Like-4-mediated Notch1 activation induces a stronger Notch signal compared to when induced by Jagged2, it seems very likely that the Delta-Like-4/Notch1 interaction is also responsible for initiating human T-lineage specification, despite the abundant $J A G 2$ expression by human TECs and the potential of the protein to induce and support $\mathrm{T}$ cell development in human hematopoietic progenitor cells (Van de Walle et al., 2011).

\subsection{Induction of T-cell commitment.}

Interestingly, following this strong Notch signal that induces the Tcell specifying transcriptional program (Taghon et al., 2005; Weerkamp et al., 2006a; Van de Walle et al., 2011), a reduction in the expression of the target genes DTXI and NRARP, but not HESI and $M Y C$, is observed in human thymocytes as they become Tlineage committed progenitors. Since those two genes are very sensitive to small changes in Notch signaling intensities (Van de Walle et al., 2009), this suggests that Notch signal strength is reduced during this transition. In addition, given that both Nrarp and Deltex 1 are considered to be negative regulators of the Notch signaling pathway, 
silencing of the genes that code for these proteins might be sufficient, and perhaps critical, to allow further Notch-dependent human $\mathrm{T}$ cell differentiation, during which the Notch signal is still sufficiently strong to allow expression of other Notch targets. Consistent with that idea, various experiments from different labs have shown that a reduction in Notch signal strength in uncommitted $\mathrm{CD} 34^{+} \mathrm{CD} 1^{-}$human $\mathrm{T}$-lineage progenitor cells allows and perhaps even enhances further differentiation into DP thymocytes (Van de Walle et al., 2009; Magri et al., 2009; Dontje et al., 2006). While our lab used graded dosages of GSI in the OP9-DLL1 coculture system, similar results were obtained when human $\mathrm{CD} 34^{+} \mathrm{CD} 1^{-}$uncommitted thymocytes were plated on OP9 cells expressing JAG1 (Dontje et al., 2006), the weakest Notch1 ligand (Van de Walle et al., 2011) but with the potential to induce HESI expression (Neves et al., 2006; Van de Walle et al., 2011). In such conditions of weakened Notch activation, human $\mathrm{T}$-lineage progenitor cells can differentiate fully into $\mathrm{CD}^{+}{ }^{+} \mathrm{TCR} \alpha \beta^{+}$thymocytes ((Dontje et al., 2006) and our own unpublished results). Given that $J A G 2$, but not $J A G 1$, is abundantly expressed by human cTECs that are mediating these stages of $T$ cell development, and given that Jagged2 is a weaker activator of Notch1 compared to Delta-Like-4, a change in ligand-mediated Notch1 activation from Delta-Like-4 to Jagged 2 might be responsible for reducing Notch activation upon $\mathrm{T}$ cell commitment in vivo. Alternatively, a local reduction in Delta-Like-4 density may also be regulating this process. Importantly, one also has to consider that the additional presence of the Notch3 receptor in these cells may alter the balance of Notch signaling activity. While Delta-Like-4 does not seem to be a good ligand for this receptor in the mouse (Suliman et al., 2011), it remains to be investigated whether Delta-Like-4 and/or Jagged2 can bind and activate Notch3 in humans. This is particularly important since Notch3 has been suggested to be a negative regulator of Notch1 activation (Beatus et al., 1999), suggesting that Notch3 activation might be another mechanism to down-modulate Notch1 activity. Thus, multiple changes in Notch receptor/ligand interactions can occur that might regulate the reduction in Notch signaling activity that seems involved in supporting the further development of $\mathrm{T}$ lineage specified human $\mathrm{T}$ cell progenitors. 
Strikingly, even in the absence of Notch signaling, uncommitted human thymocytes can generate CD8 $\beta$ expressing DP cells - even $\mathrm{CD} 3^{+} \mathrm{TCR}-\alpha \beta^{+}$cells when provided with a rearranged TCR $-\beta$ chain, although very inefficient due to lack of Notch-dependent proliferation and/or survival (Taghon et al., 2009). While we do not wish to imply that Notch signaling is no longer involved in further $\mathrm{T}$ cell differentiation (as also discussed further in this review), it does illustrate that other molecular mechanisms might be more important for driving further developmental progression. This may involve the activity of critical T-lineage transcription factors such as TCF-1, GATA-3 and BCL11b (Verbeek et al., 1995; Weber et al., 2011; Ting et al., 1996; Taghon et al., 2001; Taghon et al., 2007; Hosoya et al., 2009; Li et al., 2010a; Li et al., 2010b; Ikawa et al., 2010). Such mechanisms might also be recruited to silence the Notch target genes DTX1 and NRARP, while the Notch signaling activity itself, as measured by the amount of ICN that is released, remains at its initial signaling strength. This could be another mechanism through which Notch target genes are regulated differentially. While this has to be investigated further, the function of these Notch target genes during $\mathrm{T}$ cell development also remains unclear. Understanding this should also help to explain their specific expression profile at this early stage of human $\mathrm{T}$ cell development. In each case, Notch does not seem to be essential to induce human T-cell commitment in previously T-lineage specified progenitors in the absence of exogenous, non T-lineage, cytokines that can drive alternative lineage potential (De Smedt et al., 2005; De Smedt et al., 2007; Taghon et al., 2009; Magri et al., 2009). Given that the only function of the thymus is to give rise to $\mathrm{T}$ cells, it rather seems that the high initial levels of Notch signaling in human are important to expand the initial pool of uncommitted T-lineage specified progenitors that are generated from the limited number of TSPs.

Strikingly, the peak of DTXI and NRARP expression in uncommitted human thymocytes is in sharp contrast to the gradual increase in expression that is observed for all Notch target genes up to the DN3a stage during mouse $\mathrm{T}$ cell development. Consistent with that, also functional studies with mouse T-lineage progenitors reveal that strong Notch signaling remains essential for inducing murine $T$ cell commitment and further differentiation into DP $\alpha \beta$-lineage cells. 
Reduction (Lehar et al., 2005) or complete inhibition (Schmitt et al., 2004; Feyerabend et al., 2009) of Notch signal strength results in alternative lineage differentiation or cell death when initiated with uncommitted progenitor cells. It is intriguing that this 'lock-down' of T-lineage commitment in mouse and human is so differentially dependent on Notch signaling. While it is difficult to compare Notch signaling intensities across species, one explanation could be that the required signaling thresholds to mediate these events are different between mouse and human.

\subsection{TCR rearrangements, $\beta$-selection and beyond.}

Importantly, Notch signaling remains essential following human $\mathrm{T}$ cell commitment to support TCR rearrangements and proliferation of the cells. At this point in development, thymocytes start to express the necessary genes to allow gene recombination at the TCRD, $-G$ and $-B$ loci, such as $I L 7 R$ and the $R A G$ genes, as well as PTCRA to allow immediate induction of preTCR signaling and subsequent $\beta$-selection upon the generation of an in-frame TCR- $\beta$ chain. Consistent with a clear requirement for Notch signaling to support human TCR- $\beta$ chain rearrangements (De Smedt et al., 2005), also PTCRA expression seems Notch dependent, although we could only observe a small reduction in PTCRA expression upon Notch inhibition in human thymocytes using GSI (Van de Walle et al., 2009) or DNMAML1 overexpression (Figure 3). While a conserved CSL binding site has been detected in both human and mouse (Reizis and Leder, 2002), PTCRA expression in human seems at least equally dependent on other regulatory inputs since its expression drops 7 fold in conditions of excess Notch stimulation compared to ex vivo isolated cells (Van de Walle et al., 2009). Somewhat inconsistent with this critical role for Notch in the generation of a human preTCR complex is the notion that expression of $R A G 1$ and -2 , genes equally required to generate a functional rearranged TCR- $\beta$ chain, is enhanced upon removal of Notch signaling (Figure 3 and (Van de Walle et al., 2009)). In our current experimental setting, this may however also reflect the requirement for removal of Notch signaling 
following $\beta$-selection to allow TCR $\alpha$ gene rearrangements. Whether or not Notch is involved in TCR rearrangements of the TCRD and $G$ gene segments is presently unclear. As such, the precise role for Notch signaling during all of these recombination processes remains to be established. It is intriguing to observe that NOTCH3 displays a very similar expression profile as both $R A G$ genes, suggesting that this receptor might be involved in their regulation. As mentioned above, since Notch1 and Notch3 have been proposed to play opposing roles with respect to the activation of Notch target genes (Beatus et al., 1999), the interplay between both receptors might be involved in the apparent differential Notch dependency of for instance PTCRA on the one hand and RAG1 and RAG2 on the other hand. While both assumingly compete for interaction with CSL, they might attract other co-activators that differentially affect the transcriptional activity of each Notch receptor specific activation complex. Notch1 and Notch3 differ with respect to their trans-activation domain but little is known about its functional importance. Chromatin-immunoprecipitation studies should be able to provide some insights into this in the near future.
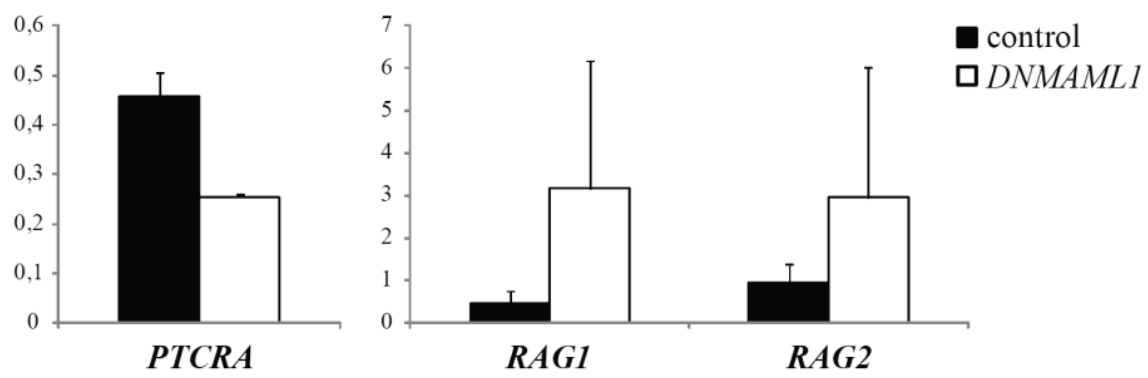

Fig. 3. Inconsistent Notch-dependent regulation of genes critical for preTCR formation during human $\mathrm{T}$ cell development.

During the rearrangement processes, thymocytes do not cycle due to a high risk of DNA damage that could be induced by the recombinase activity of the RAG proteins that are present in the cells at that particular stage. As such, repression of $R A G$ expression through Notch signaling makes sense as Notch activity generally induces proliferation in immature thymocytes. Whether or not Notch signaling is required for survival of the TCR rearranging cells during these 
stages has not been thoroughly investigated in humans. While it is clear that Notch signaling is critical for the long-term survival of human thymocytes, it is not well-established whether this is mediated directly through Notch signaling events that regulate glucose metabolism as shown for mouse DN3 thymocytes (Ciofani and ZunigaPflucker, 2005), or rather indirectly due to the lack of other critical survival signals such as for instance provided through TCR signaling (De Smedt et al., 2005). Expression of MYC, coding for an important transcriptional regulator of genes involved in cellular growth and survival, does seem to be Notch-dependent during these stages of human $\mathrm{T}$ cell development, suggesting that Notch at least partially regulates these cellular processes during early human thymocyte development. However, while a slight increase in the frequency of apoptotic cells has been observed upon Notch removal in the OP9 stromal coculture system (Magri et al., 2009), such an increase in cell death is less obvious when a more physiological system with a thymic microenvironment is used, suggesting that other survival signals besides Notch might prove to be more important (De Smedt et al., 2005). Given that the mouse experiments that revealed a requirement for Notch signaling in regulating the glucose metabolism were performed in the OP9 coculture system (Ciofani and ZunigaPflucker, 2005), it would be of interest to confirm these findings in a thymic environment. Intriguingly, Notch1 deletion in vivo at the DN2 to DN3 transition of mouse T cell development does permit survival of preTCR deficient $\alpha \beta$-lineage DN4-like cells that resemble post $\beta$-selection thymocytes, suggesting that other signals beside Notch mediate in vivo survival of these immature cells (Wolfer et al., 2002). On the other hand, complete inhibition of canonical Notch signaling using continuous DNMAML1 expression in DN3 thymocytes in vivo does reveal a more severe effect on early thymocyte survival (Maillard et al., 2006). It seems unlikely that the differential outcome between both approaches involves any Notch3 activation that could provide compensatory Notch signals (Shi et al., 2011). Nevertheless, the critical role that Notch signaling seems to play at this stage of mouse $\mathrm{T}$ cell development, together also with its requirement to support TCR- $\beta$ rearrangements (Wolfer et al., 2002) and to positively regulate PTCRA expression, fits with the peak in Notch target gene expression that is observed in these DN3a thymocytes. Thus, if we consider the peak of Notch signaling intensity, de- 
termined by the expression level of downstream target genes, as a measurement for deciphering the stage at which Notch activity might play its most significant role during $\mathrm{T}$ cell development, this might help to explain why this pathway seems to play a less critical role in the survival of early human thymocytes, compared to in mouse.

Also at the $\beta$-selection checkpoint, Notch does not seem as stringently required for the differentiation of human thymocytes compared to in mouse. In the absence of Notch signaling prior to successful TCR- $\beta$ rearrangement, thymocytes that receive an exogenously provided TCR- $\beta$ chain will further differentiate into CD $8 \beta^{+}$DP thymocytes that will subsequently rearrange the TCR- $\alpha$ chain to become TCR- $\alpha \beta^{+} \mathrm{CD} 3^{+}$cells (Taghon et al., 2009). While Notch does seem critical for appropriate proliferation of the cells in the OP9 coculture system - we cannot exclude that this apparent Notch-dependent proliferation is a result of lack of other proliferative signals that are present in vivo - such further differentiation in the absence of Notch has not been observed in the mouse (Ciofani et al., 2004; Taghon et al., 2006; Garbe et al., 2006). Consistent with above, this may also be the result of a more robust survival of human thymocytes in the absence of Notch activity. In each case, Notch signaling does not seem to be as stringently required during human as compared to during mouse $\beta$-selection.

Following $\beta$-selection, there is no evidence at present that Notch activity is critically required for the further differentiation of human thymocytes into functionally mature T cells, but this hasn't been thoroughly investigated yet. While $\mathrm{NOTCH}$, but not $\mathrm{NOTCH1}$, is specifically upregulated in human DP thymocytes, none of the wellcharacterized Notch target genes seem to be induced, suggesting that this receptor is either not activated, or that it does not have the potential to activate these genes (Beatus et al., 1999). Further work, in which $\mathrm{NOTCH} 3$ can be targeted specifically, will be required to determine if this receptor plays a functional role at this stage of human T cell development. 


\section{TCR- $\alpha \beta$ versus TCR- $\gamma \delta$ lineage choice}

Besides the main population of TCR- $\alpha \beta \mathrm{T}$ cells that differentiate within the thymus, a subset of T cells expressing TCR- $\gamma \delta$ also develops during intrathymic $\mathrm{T}$ cell differentiation, although these cells display more innate-like lymphocyte properties. Although $\gamma \delta \mathrm{T}$ cells also circulate within the blood like their $\alpha \beta$-lineage counterparts, they probably have a more prominent role in mucosa-associated tissues within the body. In contrast to TCR- $\alpha \beta \mathrm{T}$ cells that belong to the adaptive immune system and have the potential as a family to recognize virtually all possible antigens through their high diversity in TCRs, $\gamma \delta \mathrm{T}$ cells recognize more structural and less-diverse antigens. As mentioned above, $\gamma \delta \mathrm{T}$ cells branch of from the 'mainstream' $\alpha \beta$-lineage pathway during the $\mathrm{CD}_{3} 4^{+} \mathrm{CD} 1^{+}$and $\mathrm{CD} 4^{+} \mathrm{CD} 8 \alpha \alpha^{-} /^{+} \mathrm{CD} 28^{-}$stages of human $\mathrm{T}$ cell development when $T C R D,-G$ and $-B$ gene segments rearrange (Van de Walle et al., 2009; Joachims et al., 2006). Whether they differentiate through a $\mathrm{CD} 28^{+}$or $\mathrm{CD} 71^{+}$stage prior to TCR expression is presently unclear. Since newly generated $\gamma \delta$ T cells are not as proliferative as preTCR selected $\alpha \beta$-lineage thymocytes, such a transient stage might be difficult to identify, also because the full TCR complex is presumably immediately expressed.

Human $\gamma \delta$ T cells preferentially develop in conditions of high Notch activation and this was initially demonstrated using ICN overexpression studies (De Smedt et al., 2002; Garcia-Peydro et al., 2003). Since these results were inconsistent with the proposed less critical role for Notch in mouse $\gamma \delta \mathrm{T}$ cell development (Robey et al., 1996; Doerfler et al., 2001), it raised the issue whether these superficial Notch signaling levels provided any insights into the normal physiological role of Notch in this developmental process in human. Importantly, OP9 coculture experiments with human progenitors later confirmed these findings and showed, not only that high Notch signaling favors $\gamma \delta$ over $\alpha \beta$-lineage differentiation (Van de Walle et al., 2009 ), but also that virtually no $\gamma \delta$ T cells can develop from human T-lineage specified or T-cell committed progenitors in the absence of Notch signaling (Taghon et al., 2009). Since such an approach 
was more compatible with experiments that had been performed with mouse T-lineage precursors, this provided more robust insights into the differential Notch signaling requirements between mouse and human $\gamma \delta$ T cells. Consistent with the hypothesis that Notch signaling is most critical for human $\gamma \delta \mathrm{T}$ cell development, we did observe a slightly increased expression of the Notch target genes DTX1, HES1, NRARP and MYC in $\gamma \delta$-compared to $\alpha \beta$-lineage cells, although this level was still reduced compared to in early $\mathrm{CD} 34^{+} \mathrm{CD} 1^{-}$human thymocytes (Van de Walle et al., 2009). In addition to these genes, RUNX3 showed an even more interesting expression pattern. While $R U N X 3$ expression is high in $\mathrm{CD} 34^{+} \mathrm{CD} 1^{-}$ uncommitted thymocytes and downregulated upon the induction of $\mathrm{T}$-cell commitment in $\mathrm{CD} 34^{+} \mathrm{CD} 1^{+}$thymocytes, $R U N X 3$ levels reach an equally high level in $\gamma \delta$-lineage cells compared to uncommitted $\mathrm{CD} 34^{+} \mathrm{CD} 1^{-}$thymocytes. While there is currently no direct evidence that this gene is a direct Notch target gene, GSI titration experiments did suggest some degree of Notch dependent regulation in CD34 human postnatal thymocytes (Van de Walle et al., 2009), raising the possibility that RUNX3 mediates the Notch driven human $\gamma \delta$-lineage differentiation.

The choice of early T-lineage specified progenitors to develop along the $\gamma \delta$ - or $\alpha \beta$-differentiation pathways has been extensively studied in the mouse over the past years and has been recently reviewed in depth (Ciofani and Zuniga-Pflucker, 2010; Kreslavsky et al., 2010; Lee et al., 2010; Taghon and Rothenberg, 2008). Overall, the consensus is that the outcome of TCR rearrangements is not the sole determinant of the final lineage outcome. Following rearrangements, signaling through the generated $\gamma \delta$ - or preTCR can still alter the TCR-predicted lineage outcome as a strong TCR-signal will drive further differentiation along the DN $\gamma \delta$-pathway, while a weaker TCR signal will promote DP $\alpha \beta$-lineage differentiation. Downstream of the TCR, Id3 is a critical mediator that translates the strength of the TCR signal into a developmental lineage choice by modulating E protein activity (Lee et al., 2010). However, other signaling pathways have been shown to integrate with TCR signaling to impact the resulting lineage outcome, also through altering $\mathrm{E}$ protein activity. In this context, strong Notch signals have been shown to be 
essential to promote $\alpha \beta$-lineage differentiation in the mouse, as characterized by the generation of DP thymocytes, following preTCR signaling. In contrast, $\gamma \delta$-lineage differentiation does not require Notch signaling in addition to the strong TCR signal to allow further differentiation into mature $\mathrm{DN} \gamma \delta \mathrm{T}$ cells.

As also discussed earlier, preTCR driven differentiation of human pre- $\beta$-selection thymocytes into true $\mathrm{CD} 4^{+} \mathrm{CD} 8 \beta^{+}$DP thymocytes occurs more efficiently in conditions of lower Notch activation compared to conditions of high Notch signaling activity, illustrating a clear difference in Notch signaling requirement for human compared to mouse $\alpha \beta$-lineage cells. While it was clearly illustrated in the mouse that differentiation and proliferation at this stage of $\mathrm{T}$ cell development are clearly linked and both Notch dependent (Kreslavsky et al., 2008), similar experiments show that both of these processes are clearly uncoupled in human. Further differentiation of pre- $\beta$-selection thymocytes into 'true' $\mathrm{CD} 4^{+} \mathrm{CD} 8 \alpha \beta^{+} \mathrm{DP}$ cells in human is not only independent on Notch signaling activity, it is also uncoupled of proliferation as illustrated through CFSE experiments (Figure 4). Strong Notch activation in conjunction with preTCR signaling results in the maintenance of a DN phenotype and delayed differentiation, which is in contrast to $\mathrm{T}$ cell development in the mouse (Taghon et al., 2009; Van Coppernolle et al., 2012). With respect to the influence of Notch signal strength on human $\gamma \delta$ T cell development, it is currently known that maturation of immature $\mathrm{CD} 1^{+} \mathrm{TCR} \gamma \delta^{+}$thymocytes into mature $\gamma \delta \mathrm{T}$ cells can occur virtually equally efficient in the presence or absence of Notch signaling (Van Coppernolle et al., 2012). However, it is not clear yet how Notch signaling activity affects the $\gamma \delta$ - versus $\alpha \beta$-lineage choice in conjunction with strong TCR signaling since transduction experiments with a specific $\gamma \delta$ TCR have not been performed in human. 

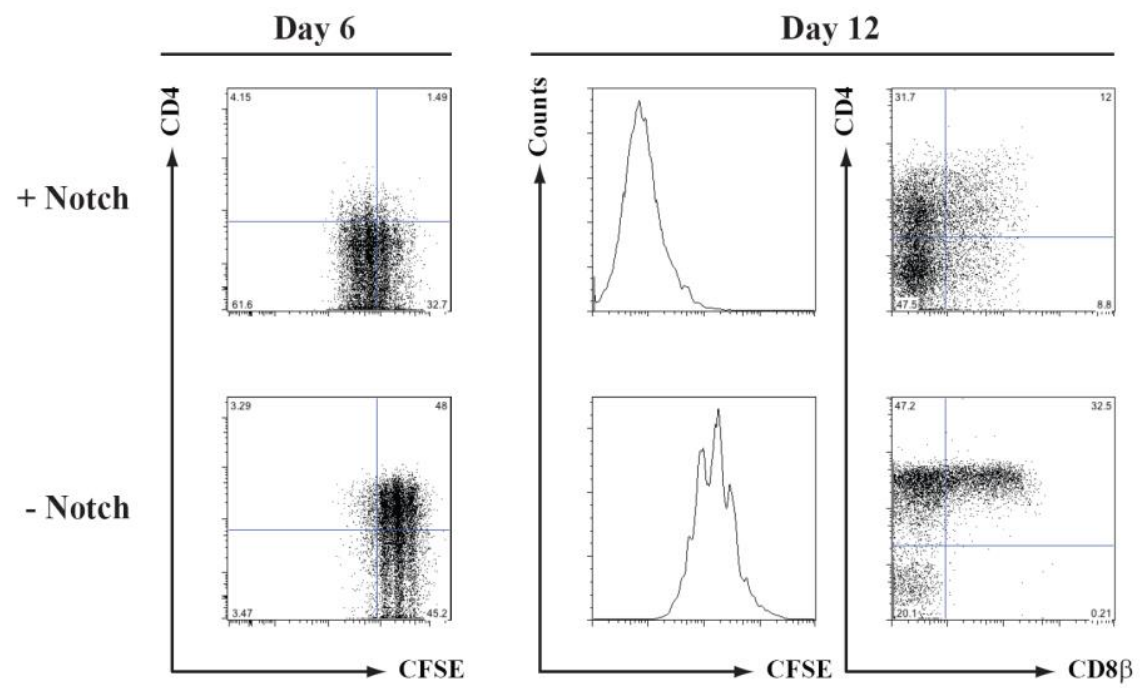

Fig. 4 Uncoupling of proliferation and differentiation during human $\mathbf{T}$ cell development. Human $\mathrm{CD} 34^{+}$postnatal thymocytes were CFSE labeled following purification and cocultured on OP9-DL1 (+ Notch) or OP9-control (- Notch) stromal cells. Cultures were analysed after 6 or 12 days and stained for $\mathrm{CD} 4$ and $\mathrm{CD} 8 \beta$, as indicated.

While the TCR signal strength model explains a lot of the experimental data that has been provided in light of this developmental choice, it is safe to predict that results of the initial TCR rearrangements in immature thymocytes will determine the developmental outcome of a large portion of the cells that have generated a $\gamma \delta$ or preTCR (Buer et al., 1997). Thus, the mechanisms that control these TCR rearrangements provide a first insight into the $\alpha \beta$ versus $\gamma \delta$ Tcell lineage choice. Importantly, while a critical role for Notch in $T C R B$ rearrangements has been illustrated in both mouse (Wolfer et al., 2002) and human (De Smedt et al., 2005), it is unclear if TCR- $\gamma$ and $-\delta$ rearrangements depend on this signaling pathway. This obscures a clear interpretation of the early effects of Notch signaling on mouse $\mathrm{T}$ cell development since in experiments in which Notch activity was conditionally affected, deletion was induced following the initiation of $\mathrm{T}$ cell specification during which rearrangements of the TCRG and $-D$ loci are already initiated (Tanigaki et al., 2004; Radtke et al., 1999). As such, it is difficult to interpret if $\gamma \delta \mathrm{T}$ cells in the mouse might not also depend on Notch activity early on to allow these rearrangement events. Experiments with purified DN2 
subsets did reveal a clear reduction in $\gamma \delta \mathrm{T}$ cell in the absence of Notch signaling (Ciofani et al., 2004). Mechanistically, this could be mediated through regulation of IL7R expression (Gonzalez-Garcia et al., 2009) since signaling through this receptor has been shown to be essential for TCRG rearrangements (Maki et al., 1996; Durum et al., 1998). As such, high Notch signaling activity in human could promote $\gamma \delta \mathrm{T}$ cell development by preferentially inducing rearrangements at the gene segments of these TCRs (Ye et al., 2001).

Thus, Notch signaling might mediate the $\alpha \beta / \gamma \delta$-lineage choice at two distinct stages of $\mathrm{T}$ cell development. A first role may involve regulation of $T C R D,-G$ and $-B$ rearrangements in immature thymocytes prior to $\gamma \delta$ - or $\beta$-selection, while a second role becomes apparent following these TCR-mediated selection processes as Notch activity synergizes with these $\gamma \delta$ and preTCR signaling events. As such, further studies will be essential to determine how different the role of Notch signaling is in these events during human and mouse $\mathrm{T}$ cell development.

\section{Conclusion}

While the current experimental data reveals both similar and alternative roles for the Notch signaling pathway during human $\mathrm{T}$ cell development compared to mouse, much work is still required to fully understand the precise mechanisms through which Notch signaling influences each of these early stages of this developmental process. While the role of differential Notch receptor/ligands remains to be explored, also the integration of various molecular mechanisms downstream of the Notch receptors into the global transcriptional network that drives human $\mathrm{T}$ cell development is still in its infancy. While much more progress has been made with respect to these issues in the mouse (Kueh and Rothenberg, 2012; Radtke et al., 2010; Maillard et al., 2005; Yuan et al., 2010), we anticipate that novel technical advances, that enable for instance knockout and genereporter approaches in human ES cells, will yield more definitive in- 
sights into these processes (Timmermans et al., 2009; Galic et al., 2006; Hockemeyer et al., 2009; Hockemeyer et al., 2011). Given that recent insights suggest important regulatory differences for the Notch signaling pathway in human versus mouse T-acute lymphoblastic leukemia (Wang et al., 2011), tackling these questions is of vital importance for understanding normal and malignant developmental processes in human.

\section{Acknowledgments}

The authors wish to thank Jean Plum for critical reading of the manuscript. Work on this subject by the Taghon lab is funded by a research grant from the Fund for Scientific Research Flanders (FWO), as well as by its Odysseus program. IVdW is supported by a grant from the Special Fund for Scientific Research (BOF) of the Ghent University and TT by a fellowship of the FWO.

References

Awong,G., Herer,E., Surh,C.D., Dick,J.E., La Motte-Mohs,R.N., and Zuniga-Pflucker,J.C. (2009). Characterization in vitro and engraftment potential in vivo of human progenitor $\mathrm{T}$ cells generated from hematopoietic stem cells. Blood 114, 972-982.

Beatus,P., Lundkvist,J., Oberg,C., and Lendahl,U. (1999). The notch 3 intracellular domain represses notch 1-mediated activation through Hairy/Enhancer of split (HES) promoters. Development 126, 3925-3935.

Benne,C., Lelievre,J.D., Balbo,M., Henry,A., Sakano,S., and Levy,Y. (2009). Notch increases T/NK potential of human hematopoietic progenitors and inhibits $B$ cell differentiation at a pro-B stage. Stem Cells 27, 1676-1685.

Blom,B. and Spits,H. (2006). Development of human lymphoid cells. Annu. Rev. Immunol. 24, 287-320.

Buer,J., Aifantis,I., DiSanto,J.P., Fehling,H.J., and von Boehmer,H. (1997). Role of different T cell receptors in the development of pre-T cells. J. Exp. Med. 185, 1541-1547.

Carrasco,Y.R., Trigueros,C., Ramiro,A.R., de Yebenes,V., and Toribio,M.L. (1999). Beta-selection is associated with the onset of CD8beta chain expression on CD4(+)CD8alphaalpha(+) pre-T cells during human intrathymic development. Blood 94, 3491-3498.

Ciofani,M., Schmitt,T.M., Ciofani,A., Michie,A.M., Cuburu,N., Aublin,A., Maryanski,J.L., and Zuniga-Pflucker,J.C. (2004). Obligatory role for cooperative signaling by pre-TCR and Notch during thymocyte differentiation. J. Immunol. 172, 5230-5239.

Ciofani,M. and Zuniga-Pflucker,J.C. (2005). Notch promotes survival of pre-T cells at the betaselection checkpoint by regulating cellular metabolism. Nat. Immunol. 6, 881-888.

Ciofani,M. and Zuniga-Pflucker,J.C. (2010). Determining gammadelta versus alphass T cell development. Nat. Rev. Immunol. 10, 657-663.

David-Fung,E.S., Yui,M.A., Morales,M., Wang,H., Taghon,T., Diamond,R.A., and Rothenberg,E.V. (2006). Progression of regulatory gene expression states in fetal and adult pro-T-cell development. Immunol. Rev. 209, 212-236. 
De Smedt,M., Hoebeke,I., and Plum,J. (2004). Human bone marrow CD34+ progenitor cells mature to T cells on OP9-DL1 stromal cell line without thymus microenvironment. Blood Cells Mol. Dis. 33, 227-232.

De Smedt,M., Hoebeke,I., Reynvoet,K., Leclercq,G., and Plum,J. (2005). Different thresholds of Notch signaling bias human precursor cells toward B-, NK-, monocytic/dendritic-, or T-cell lineage in thymus microenvironment. Blood 106, 3498-3506.

De Smedt,M., Reynvoet,K., Kerre,T., Taghon,T., Verhasselt,B., Vandekerckhove,B., Leclercq,G., and Plum,J. (2002). Active form of Notch imposes T cell fate in human progenitor cells. J. Immunol. 169, 3021-3029.

De Smedt,M., Taghon,T., Van de Walle,I., De Smet,G., Leclercq,G., and Plum,J. (2007). Notch signaling induces cytoplasmic CD3 epsilon expression in human differentiating NK cells. Blood 110, 2696-2703.

Dik,W.A., Pike-Overzet,K., Weerkamp,F., de Ridder,D., de Haas,E.F., Baert,M.R., van der Spek,P., Koster,E.E., Reinders,M.J., van Dongen,J.J., Langerak,A.W., and Staal,F.J. (2005). New insights on human $T$ cell development by quantitative $T$ cell receptor gene rearrangement studies and gene expression profiling. J. Exp. Med. 201, 1715-1723.

Doerfler,P., Shearman,M.S., and Perlmutter,R.M. (2001). Presenilin-dependent gammasecretase activity modulates thymocyte development. Proc. Natl. Acad. Sci. U. S. A 98, 93129317.

Dontje,W., Schotte,R., Cupedo,T., Nagasawa,M., Scheeren,F., Gimeno,R., Spits,H., and Blom,B. (2006). Delta-like1-induced Notch1 signaling regulates the human plasmacytoid dendritic cell versus T-cell lineage decision through control of GATA-3 and Spi-B. Blood 107, 24462452.

Doulatov,S., Notta,F., Eppert,K., Nguyen,L.T., Ohashi,P.S., and Dick,J.E. (2010). Revised map of the human progenitor hierarchy shows the origin of macrophages and dendritic cells in early lymphoid development. Nat. Immunol. 11, 585-593.

Durum,S.K., Candeias,S., Nakajima,H., Leonard,W.J., Baird,A.M., Berg,L.J., and Muegge,K. (1998). Interleukin 7 receptor control of T cell receptor gamma gene rearrangement: role of receptor-associated chains and locus accessibility. J. Exp. Med. 188, 2233-2241.

Feyerabend,T.B., Terszowski,G., Tietz,A., Blum,C., Luche,H., Gossler,A., Gale,N.W., Radtke,F., Fehling,H.J., and Rodewald,H.R. (2009). Deletion of Notch1 converts pro-T cells to dendritic cells and promotes thymic B cells by cell-extrinsic and cell-intrinsic mechanisms. Immunity. 30, 67-79.

Galic,Z., Kitchen,S.G., Kacena,A., Subramanian,A., Burke,B., Cortado,R., and Zack,J.A. (2006). T lineage differentiation from human embryonic stem cells. Proc. Natl. Acad. Sci. U. S. A 103, 11742-11747.

Galy,A., Travis,M., Cen,D., and Chen,B. (1995). Human T, B, natural killer, and dendritic cells arise from a common bone marrow progenitor cell subset. Immunity. 3, 459-473.

Garbe,A.I., Krueger,A., Gounari,F., Zuniga-Pflucker,J.C., and von Boehmer,H. (2006). Differential synergy of Notch and $T$ cell receptor signaling determines alphabeta versus gammadelta lineage fate. J. Exp. Med. 203, 1579-1590.

Garcia-Peydro,M., de Yebenes,V., and Toribio,M.L. (2003). Sustained Notch1 signaling instructs the earliest human intrathymic precursors to adopt a gammadelta T-cell fate in fetal thymus organ culture. Blood 102, 2444-2451.

Ghisi,M., Corradin,A., Basso,K., Frasson,C., Serafin,V., Mukherjee,S., Mussolin,L., Ruggero,K., Bonanno,L., Guffanti,A., De Bellis,G., Gerosa,G., Stellin,G., D'Agostino,D.M., Basso,G., Bronte,V., Indraccolo,S., Amadori,A., and Zanovello,P. (2011). Modulation of microRNA expression in human T-cell development: targeting of NOTCH3 by miR-150. Blood 117, 70537062.

Gonzalez-Garcia,S., Garcia-Peydro,M., Martin-Gayo,E., Ballestar,E., Esteller,M., Bornstein,R., de la Pompa,J.L., Ferrando,A.A., and Toribio,M.L. (2009). CSL-MAML-dependent Notch1 
signaling controls $T$ lineage-specific IL-7R\{alpha\} gene expression in early human thymopoiesis and leukemia. J. Exp. Med. 206, 779-791.

Gotter,J., Brors,B., Hergenhahn,M., and Kyewski,B. (2004). Medullary epithelial cells of the human thymus express a highly diverse selection of tissue-specific genes colocalized in chromosomal clusters. J. Exp. Med. 199, 155-166.

Green,M.D., Chen,A., Nostro,M.C., d'Souza,S.L., Schaniel,C., Lemischka,I.R., Gouon-Evans,V., Keller,G., and Snoeck,H.W. (2011). Generation of anterior foregut endoderm from human embryonic and induced pluripotent stem cells. Nat. Biotechnol. 29, 267-272.

Haddad,R., Guimiot,F., Six,E., Jourquin,F., Setterblad,N., Kahn,E., Yagello,M., Schiffer,C., AndreSchmutz,I., Cavazzana-Calvo,M., Gluckman,J.C., Delezoide,A.L., Pflumio,F., and Canque,B. (2006). Dynamics of thymus-colonizing cells during human development. Immunity. 24, 217 230.

Hao,Q.L., George,A.A., Zhu,J., Barsky,L., Zielinska,E., Wang,X., Price,M., Ge,S., and Crooks,G.M. (2008). Human intrathymic lineage commitment is marked by differential CD7 expression: identification of CD7- lympho-myeloid thymic progenitors. Blood 111, 1318-1326.

Hao,Q.L., Zhu,J., Price,M.A., Payne,K.J., Barsky,L.W., and Crooks,G.M. (2001). Identification of a novel, human multilymphoid progenitor in cord blood. Blood 97, 3683-3690.

Heinzel,K., Benz,C., Martins,V.C., Haidl,I.D., and Bleul,C.C. (2007). Bone marrow-derived hemopoietic precursors commit to the $\mathrm{T}$ cell lineage only after arrival in the thymic microenvironment. J. Immunol. 178, 858-868.

Hirata,H., Yoshiura,S., Ohtsuka,T., Bessho,Y., Harada,T., Yoshikawa,K., and Kageyama,R. (2002) Oscillatory expression of the bHLH factor Hes1 regulated by a negative feedback loop. Science 298, 840-843.

Hockemeyer,D., Soldner,F., Beard,C., Gao,Q., Mitalipova,M., DeKelver,R.C., Katibah,G.E., Amora,R., Boydston,E.A., Zeitler,B., Meng,X., Miller,J.C., Zhang,L., Rebar,E.J., Gregory,P.D., Urnov,F.D., and Jaenisch,R. (2009). Efficient targeting of expressed and silent genes in human ESCs and iPSCs using zinc-finger nucleases. Nat. Biotechnol. 27, 851-857.

Hockemeyer,D., Wang,H., Kiani,S., Lai,C.S., Gao,Q., Cassady,J.P., Cost,G.J., Zhang,L., Santiago,Y., Miller,J.C., Zeitler,B., Cherone,J.M., Meng,X., Hinkley,S.J., Rebar,E.J., Gregory,P.D., Urnov,F.D., and Jaenisch,R. (2011). Genetic engineering of human pluripotent cells using TALE nucleases. Nat. Biotechnol. 29, 731-734.

Hoebeke,I., De Smedt,M., Stolz,F., Pike-Overzet,K., Staal,F.J., Plum,J., and Leclercq,G. (2007). TB- and NK-lymphoid, but not myeloid cells arise from human CD34(+)CD38(-)CD7(+) common lymphoid progenitors expressing lymphoid-specific genes. Leukemia 21, 311-319.

Hosoya,T., Kuroha,T., Moriguchi,T., Cummings,D., Maillard,I., Lim,K.C., and Engel,J.D. (2009). GATA-3 is required for early T lineage progenitor development. J. Exp. Med. 206, 2987-3000.

Hozumi,K., Mailhos,C., Negishi,N., Hirano,K.I., Yahata,T., Ando,K., Zuklys,S., Hollander,G.A., Shima,D.T., and Habu,S. (2008). Delta-like 4 is indispensable in thymic environment specific for T cell development. J. Exp. Med.

Hozumi,K., Negishi,N., Suzuki,D., Abe,N., Sotomaru,Y., Tamaoki,N., Mailhos,C., Ish-Horowicz,D., Habu,S., and Owen,M.J. (2004). Delta-like 1 is necessary for the generation of marginal zone $B$ cells but not T cells in vivo. Nat. Immunol. 5, 638-644.

Ikawa,T., Hirose,S., Masuda,K., Kakugawa,K., Satoh,R., Shibano-Satoh,A., Kominami,R., Katsura,Y., and Kawamoto,H. (2010). An essential developmental checkpoint for production of the T cell lineage. Science 329, 93-96.

Ikawa,T., Kawamoto,H., Goldrath,A.W., and Murre,C. (2006). E proteins and Notch signaling cooperate to promote T cell lineage specification and commitment. J. Exp. Med. 203, 13291342.

Jaleco,A.C., Neves,H., Hooijberg,E., Gameiro,P., Clode,N., Haury,M., Henrique,D., and Parreira,L. (2001). Differential effects of Notch ligands Delta-1 and Jagged-1 in human lymphoid differentiation. J. Exp. Med. 194, 991-1002. 
Joachims,M.L., Chain,J.L., Hooker,S.W., Knott-Craig,C.J., and Thompson,L.F. (2006). Human alpha beta and gamma delta thymocyte development: TCR gene rearrangements, intracellular TCR beta expression, and gamma delta developmental potential--differences between men and mice. J. Immunol. 176, 1543-1552.

Klein,F., Feldhahn,N., Lee,S., Wang,H., Ciuffi,F., von Elstermann,M., Toribio,M.L., Sauer,H., Wartenberg,M., Barath,V.S., Kronke,M., Wernet,P., Rowley,J.D., and Muschen,M. (2003). T lymphoid differentiation in human bone marrow. Proc. Natl. Acad. Sci. U. S. A 100, 67476752.

Koch,U., Fiorini,E., Benedito,R., Besseyrias,V., Schuster-Gossler,K., Pierres,M., Manley,N.R., Duarte,A., Macdonald,H.R., and Radtke,F. (2008). Delta-like 4 is the essential, nonredundant ligand for Notch1 during thymic T cell lineage commitment. J. Exp. Med.

Kreslavsky,T., Garbe,A.I., Krueger,A., and von Boehmer,H. (2008). T cell receptor-instructed alphabeta versus gammadelta lineage commitment revealed by single-cell analysis. J. Exp. Med. 205, 1173-1186.

Kreslavsky,T., Gleimer,M., Garbe,A.I., and von Boehmer,H. (2010). alphabeta versus gammadelta fate choice: counting the T-cell lineages at the branch point. Immunol. Rev. 238, 169-181.

Krueger,A., Garbe,A.I., and von Boehmer,H. (2006). Phenotypic plasticity of T cell progenitors upon exposure to Notch ligands. J. Exp. Med. 203, 1977-1984.

Kueh,H.Y. and Rothenberg,E.V. (2012). Regulatory gene network circuits underlying T cell development from multipotent progenitors. Wiley. Interdiscip. Rev. Syst. Biol. Med. 4, 79102.

La Motte-Mohs,R.N., Herer,E., and Zuniga-Pflucker,J.C. (2005). Induction of T-cell development from human cord blood hematopoietic stem cells by Delta-like 1 in vitro. Blood 105, 14311439.

Lee,S.Y., Stadanlick,J., Kappes,D.J., and Wiest,D.L. (2010). Towards a molecular understanding of the differential signals regulating alphabeta/gammadelta T lineage choice. Semin. Immunol. 22, 237-246.

Lefort,N., Benne,C., Lelievre,J.D., Dorival,C., Balbo,M., Sakano,S., Coulombel,L., and Levy,Y. (2006). Short exposure to Notch ligand Delta-4 is sufficient to induce T-cell differentiation program and to increase the T cell potential of primary human CD34+ cells. Exp. Hematol. 34, 1720-1729.

Lehar,S.M., Dooley,J., Farr,A.G., and Bevan,M.J. (2005). Notch ligands Delta 1 and Jagged1 transmit distinct signals to T-cell precursors. Blood 105, 1440-1447.

Li,K., Li,Y., Wu,W., Gordon,W.R., Chang,D.W., Lu,M., Scoggin,S., Fu,T., Vien,L., Histen,G., Zheng,J., Martin-Hollister,R., Duensing,T., Singh,S., Blacklow,S.C., Yao,Z., Aster,J.C., and Zhou,B.B. (2008). Modulation of Notch signaling by antibodies specific for the extracellular negative regulatory region of NOTCH3. J. Biol. Chem. 283, 8046-8054.

Li,L., Leid,M., and Rothenberg,E.V. (2010a). An early T cell lineage commitment checkpoint dependent on the transcription factor Bcl11b. Science 329, 89-93.

Li,P., Burke,S., Wang,J., Chen,X., Ortiz,M., Lee,S.C., Lu,D., Campos,L., Goulding,D., Ng,B.L., Dougan,G., Huntly,B., Gottgens,B., Jenkins,N.A., Copeland,N.G., Colucci,F., and Liu,P. (2010b). Reprogramming of T cells to natural killer-like cells upon Bcl11b deletion. Science 329, 85-89.

Magri,M., Yatim,A., Benne,C., Balbo,M., Henry,A., Serraf,A., Sakano,S., Gazzolo,L., Levy,Y., and Lelievre,J.D. (2009). Notch ligands potentiate IL-7-driven proliferation and survival of human thymocyte precursors. Eur. J. Immunol. 39, 1231-1240.

Maillard,I., Fang,T., and Pear,W.S. (2005). Regulation of lymphoid development, differentiation, and function by the Notch pathway. Annu. Rev. Immunol. 23, 945-974.

Maillard,I., Tu,L., Sambandam,A., Yashiro-Ohtani,Y., Millholland,J., Keeshan,K., Shestova,O., Xu,L., Bhandoola,A., and Pear,W.S. (2006). The requirement for Notch signaling at the beta- 
selection checkpoint in vivo is absolute and independent of the pre-T cell receptor. J. Exp. Med. 203, 2239-2245.

Maki,K., Sunaga,S., and Ikuta,K. (1996). The V-J recombination of T cell receptor-gamma genes is blocked in interleukin-7 receptor-deficient mice. J. Exp. Med. 184, 2423-2427.

Neves,H., Weerkamp,F., Gomes,A.C., Naber,B.A., Gameiro,P., Becker,J.D., Lucio,P., Clode,N., van Dongen,J.J., Staal,F.J., and Parreira,L. (2006). Effects of Delta1 and Jagged1 on early human hematopoiesis: correlation with expression of notch signaling-related genes in CD34+ cells. Stem Cells 24, 1328-1337.

Palomero,T., Lim,W.K., Odom,D.T., Sulis,M.L., Real,P.J., Margolin,A., Barnes,K.C., O'Neil,J., Neuberg,D., Weng,A.P., Aster,J.C., Sigaux,F., Soulier,J., Look,A.T., Young,R.A., Califano,A., and Ferrando,A.A. (2006). NOTCH1 directly regulates C-MYC and activates a feed-forwardloop transcriptional network promoting leukemic cell growth. Proc. Natl. Acad. Sci. U. S. A 103, 18261-18266.

Petrie,H.T. and Zuniga-Pflucker,J.C. (2007). Zoned out: functional mapping of stromal signaling microenvironments in the thymus. Annu. Rev. Immunol. 25, 649-679.

Plum,J., De Smedt,M., Leclercq,G., Taghon,T., Kerre,T., and Vandekerckhove,B. (2008). Human intrathymic development: a selective approach. Semin. Immunopathol. 30, 411-423.

Radtke,F., Fasnacht,N., and Macdonald,H.R. (2010). Notch signaling in the immune system. Immunity. 32, 14-27.

Radtke,F., Wilson,A., Stark,G., Bauer,M., van Meerwijk,J., Macdonald,H.R., and Aguet,M. (1999). Deficient $T$ cell fate specification in mice with an induced inactivation of Notch1. Immunity. 10, 547-558.

Reizis,B. and Leder,P. (2002). Direct induction of T lymphocyte-specific gene expression by the mammalian Notch signaling pathway. Genes Dev. 16, 295-300.

Robey,E., Chang,D., Itano,A., Cado,D., Alexander,H., Lans,D., Weinmaster,G., and Salmon,P. (1996). An activated form of Notch influences the choice between CD4 and CD8 T cell lineages. Cell 87, 483-492.

Sambandam,A., Maillard,I., Zediak,V.P., Xu,L., Gerstein,R.M., Aster,J.C., Pear,W.S., and Bhandoola,A. (2005). Notch signaling controls the generation and differentiation of early $T$ lineage progenitors. Nat. Immunol. 6, 663-670.

Schmitt,T.M., Ciofani,M., Petrie,H.T., and Zuniga-Pflucker,J.C. (2004). Maintenance of T cell specification and differentiation requires recurrent notch receptor-ligand interactions. J. Exp. Med. 200, 469-479.

Shi,J., Fallahi,M., Luo,J.L., and Petrie,H.T. (2011). Nonoverlapping functions for Notch1 and Notch3 during murine steady-state thymic lymphopoiesis. Blood 118, 2511-2519.

Six,E.M., Bonhomme,D., Monteiro,M., Beldjord,K., Jurkowska,M., Cordier-Garcia,C., Garrigue,A., Dal,C.L., Rocha,B., Fischer,A., Cavazzana-Calvo,M., and Andre-Schmutz,I. (2007). A human postnatal lymphoid progenitor capable of circulating and seeding the thymus. J. Exp. Med. 204, 3085-3093.

Suliman,S., Tan,J., Xu,K., Kousis,P.C., Kowalski,P.E., Chang,G., Egan,S.E., and Guidos,C. (2011). Notch3 is dispensable for thymocyte beta-selection and Notch1-induced $T$ cell leukemogenesis. PLoS. One. 6, e24937.

Taghon,T., De Smedt,M., Stolz,F., Cnockaert,M., Plum,J., and Leclercq,G. (2001). Enforced expression of GATA-3 severely reduces human thymic cellularity. J. Immunol. 167, 44684475.

Taghon,T. and Rothenberg,E.V. (2008). Molecular mechanisms that control mouse and human TCR-alphabeta and TCR-gammadelta T cell development. Semin. Immunopathol. 30, 383398.

Taghon,T., Stolz,F., De Smedt,M., Cnockaert,M., Verhasselt,B., Plum,J., and Leclercq,G. (2002). HOX-A10 regulates hematopoietic lineage commitment: evidence for a monocyte-specific transcription factor. Blood 99, 1197-1204. 
Taghon,T., Van de Walle,I., De Smet,G., De Smedt,M., Leclercq,G., Vandekerckhove,B., and Plum,J. (2009). Notch signaling is required for proliferation but not for differentiation at a well-defined beta-selection checkpoint during human T-cell development. Blood 113, 32543263.

Taghon,T., Yui,M.A., Pant,R., Diamond,R.A., and Rothenberg,E.V. (2006). Developmental and molecular characterization of emerging beta- and gammadelta-selected pre-T cells in the adult mouse thymus. Immunity. 24, 53-64.

Taghon,T., Yui,M.A., and Rothenberg,E.V. (2007). Mast cell lineage diversion of T lineage precursors by the essential T cell transcription factor GATA-3. Nat. Immunol. 8, 845-855.

Taghon,T.N., David,E.S., Zuniga-Pflucker,J.C., and Rothenberg,E.V. (2005). Delayed, asynchronous, and reversible T-lineage specification induced by Notch/Delta signaling. Genes Dev. 19, 965-978.

Tanigaki,K., Tsuji,M., Yamamoto,N., Han,H., Tsukada,J., Inoue,H., Kubo,M., and Honjo,T. (2004). Regulation of alphabeta/gammadelta $\mathrm{T}$ cell lineage commitment and peripheral $\mathrm{T}$ cell responses by Notch/RBP-J signaling. Immunity. 20, 611-622.

Timmermans,F., Velghe,I., Vanwalleghem,L., De Smedt,M., Van Coppernolle,S., Taghon,T., Moore,H.D., Leclercq,G., Langerak,A.W., Kerre,T., Plum,J., and Vandekerckhove,B. (2009). Generation of $\mathrm{T}$ cells from human embryonic stem cell-derived hematopoietic zones. J. Immunol. 182, 6879-6888.

Ting,C.N., Olson,M.C., Barton,K.P., and Leiden,J.M. (1996). Transcription factor GATA-3 is required for development of the T-cell lineage. Nature 384, 474-478.

Tydell,C.C., vid-Fung,E.S., Moore,J.E., Rowen,L., Taghon,T., and Rothenberg,E.V. (2007). Molecular dissection of prethymic progenitor entry into the $T$ lymphocyte developmental pathway. J. Immunol. 179, 421-438.

Van Coppernolle,S., Vanhee,S., Verstichel,G., Snauwaert,S., van der Spek,A., Velghe,I., Sinnesael,M., Heemskerk,M.H., Taghon,T., Leclercq,G., Plum,J., Langerak,A.W., Kerre,T., and Vandekerckhove,B. (2012). Notch induces human T-cell receptor gammadelta+ thymocytes to differentiate along a parallel, highly proliferative and bipotent CD4 CD8 double-positive pathway. Leukemia 26, 127-138.

Van de Walle,I., De Smet,G., Gartner,M., De Smedt,M., Waegemans,E., Vandekerckhove,B., Leclercq,G., Plum,J., Aster,J.C., Bernstein,I.D., Guidos,C.J., Kyewski,B., and Taghon,T. (2011). Jagged 2 acts as a Delta-like Notch ligand during early hematopoietic cell fate decisions. Blood 117, 4449-4459.

Van de Walle,I., De Smet,G., De Smedt,M., Vandekerckhove,B., Leclercq,G., Plum,J., and Taghon,T. (2009). An early decrease in Notch activation is required for human TCRalphabeta lineage differentiation at the expense of TCR-gammadelta T cells. Blood 113, 2988-2998.

Vandekerckhove,B., Vanhee,S., Van Coppernolle,S., Snauwaert,S., Velghe,I., Taghon,T., Leclercq,G., Kerre,T., and Plum,J. (2011). In vitro generation of immune cells from pluripotent stem cells. Front Biosci. 16, 1488-1504.

Verbeek,S., Izon,D., Hofhuis,F., Robanus-Maandag,E., te Riele,H., van de Wetering,M., Oosterwegel,M., Wilson,A., Macdonald,H.R., and Clevers,H. (1995). An HMG-box-containing T-cell factor required for thymocyte differentiation. Nature 374, 70-74.

Wang,H., Zou,J., Zhao,B., Johannsen,E., Ashworth,T., Wong,H., Pear,W.S., Schug,J., Blacklow,S.C., Arnett,K.L., Bernstein,B.E., Kieff,E., and Aster,J.C. (2011). Genome-wide analysis reveals conserved and divergent features of Notch1/RBPJ binding in human and murine T-lymphoblastic leukemia cells. Proc. Natl. Acad. Sci. U. S. A 108, 14908-14913.

Weber,B.N., Chi,A.W., Chavez,A., Yashiro-Ohtani,Y., Yang,Q., Shestova,O., and Bhandoola,A. (2011). A critical role for TCF-1 in T-lineage specification and differentiation. Nature 476, 6368.

Weerkamp,F., Baert,M.R., Brugman,M.H., Dik,W.A., de Haas,E.F., Visser,T.P., de Groot,C.J., Wagemaker,G., van Dongen,J.J., and Staal,F.J. (2006a). Human thymus contains multipotent 
progenitors with T/B lymphoid, myeloid, and erythroid lineage potential. Blood 107, 31313137.

Weerkamp,F., van Dongen,J.J., and Staal,F.J. (2006b). Notch and Wnt signaling in T-lymphocyte development and acute lymphoblastic leukemia. Leukemia 20, 1197-1205.

Weng,A.P., Millholland,J.M., Yashiro-Ohtani,Y., Arcangeli,M.L., Lau,A., Wai,C., Del Bianco,C., Rodriguez,C.G., Sai,H., Tobias,J., Li,Y., Wolfe,M.S., Shachaf,C., Felsher,D., Blacklow,S.C., Pear,W.S., and Aster,J.C. (2006). c-Myc is an important direct target of Notch1 in T-cell acute lymphoblastic leukemia/lymphoma. Genes Dev. 20, 2096-2109.

Wilson,A., Macdonald,H.R., and Radtke,F. (2001). Notch 1-deficient common lymphoid precursors adopt a B cell fate in the thymus. J. Exp. Med. 194, 1003-1012.

Wolfer,A., Wilson,A., Nemir,M., Macdonald,H.R., and Radtke,F. (2002). Inactivation of Notch1 impairs VDJbeta rearrangement and allows pre-TCR-independent survival of early alpha beta Lineage Thymocytes. Immunity. 16, 869-879.

Wu,Y., Cain-Hom,C., Choy,L., Hagenbeek,T.J., de Leon,G.P., Chen,Y., Finkle,D., Venook,R., Wu,X., Ridgway,J., Schahin-Reed,D., Dow,G.J., Shelton,A., Stawicki,S., Watts,R.J., Zhang,J., Choy,R., Howard,P., Kadyk,L., Yan,M., Zha,J., Callahan,C.A., Hymowitz,S.G., and Siebel,C.W. (2010) Therapeutic antibody targeting of individual Notch receptors. Nature 464, 1052-1057.

Ye,S.K., Agata,Y., Lee,H.C., Kurooka,H., Kitamura,T., Shimizu,A., Honjo,T., and Ikuta,K. (2001). The IL-7 receptor controls the accessibility of the TCRgamma locus by Stat5 and histone acetylation. Immunity. 15, 813-823.

Yuan,J.S., Kousis,P.C., Suliman,S., Visan,I., and Guidos,C.J. (2010). Functions of notch signaling in the immune system: consensus and controversies. Annu. Rev. Immunol. 28, 343-365.

Yui,M.A., Feng,N., and Rothenberg,E.V. (2010). Fine-scale staging of T cell lineage commitment in adult mouse thymus. J. Immunol. 185, 284-293.

The final publication is available at Springer via http://dx.doi.org/10.1007/82_2012_230 